\title{
The Effect of Vacuum on Venous Drainage: an Experimental Evaluation on Pediatric Venous Cannulas and Tubing Systems
}

\author{
Vladimiro L Vida, ${ }^{1}$ A Bhattarai, ${ }^{1}$ Simone Speggiorin, ${ }^{1,2}$ Fabio Zanella, ${ }^{3}$ Giovanni Stellin ${ }^{1}$ \\ 'Pediatric and Congenital Cardiac Surgery Unit, Department of Cardiac, Thoracic and Vascular Surgery, University of Padua, \\ Italy \\ ${ }^{2}$ Cardiothoracic Surgery Department, The Great Ormond Street Hospital for Children NHS Trust, London, UK \\ ${ }^{3}$ Cardiac Perfusion Unit, University of Padua, Italy.
}

\section{ABSTRACT}

Introduction: To observe how vacuum assisted venous drainage (VAVD) may influence the flow in a cardiopulmonary bypass circuit with different size of venous lines and cannulas.

Methods: The experimental circuit was assembled to represent the cardiopulmonary bypass circuit routinely used during cardiac surgery. Wall suction was applied directly, modulated and measured into the venous reservoir. The blood flow was measured with a flow-meter positioned on the venous line. The circuit prime volume was replaced with group $\mathrm{O}$ date expired re-suspended red cells and Plasmalyte 148 to a hematocrit of $28 \%$ to $30 \%$.

Results: In an open circuit with gravity siphon venous drain, angled cannulae drain more than straight ones regardless the amount of suction applied to the venous line (16 Fr straight cannula (S) drains $90 \mathrm{ml} / \mathrm{min}$ less than a $16 \mathrm{Fr}$ angled (A) with a siphon gravity). The same flow can be obtained with lower cannula size and higher suction (i.e. $12 \mathrm{~A}$ with and $-30 \mathrm{mmHg}$ ). Tables have been created to list how the flow varies according to the size of the cannulas, the size of the venous tubes, and the amount of suction applied to the system.

Conclusions: Vacuum assisted venous drainage allows the use of smaller cannulae and venous lines to maintain a good venous return, which is very useful during minimally invasive approaches. The present study should be considered as a preliminary attempt to create a scientific-based starting point for a uniform the use of VAVD.

Keywords: cardio-pulmonary bypass; experimental study; vacuum assisted drainage.

\section{INTRODUCTION}

Vacuum assisted venous drainage (VAVD) is a well known technique widely used in both adult and pediatric cardiac surgery. During the last 10 years VAVD has been mainly used to reduce haemodilution during cardiopulmonary bypass $(\mathrm{CPB})^{1-3}$ as it allows for a "lower prime" circuit, ${ }^{4}$ and smaller venous cannulae during minimally invasive cardiac surgery (MICS) procedures without compromising patient blood flow. ${ }^{5-8}$ Combined with VAVD, the use of shorter circuits, smaller cannulae and eventually lower priming volume, is closely associated to the ability to reduce homologous blood transfusion. ${ }^{3-9}$ Indications and the use of VAVD are not uniform and differ from centre

Correspondence: Dr. Vladimiro Vida, Pediatric and Congenital Cardiac Surgery Unit, Department of Cardiac, Thoracic and Vascular Surgery, University of Padua, Via Giustiniani, 2-35128, Padua, Italy, E-mail: vladimirovida@yahoo.it, Tel: +39-0498212410, Fax: +39 049 8212409 
Vida et al. The Effect of Vacuum on Venous Drainage: an Experimental Evaluation on Pediatric Venous Cannulas and Tubing Systems

to centre according to the Institutional experience. In order to standardize our clinical practice we attempted to determine the effects of suction on the venous drainage and consequently on the blood flow dynamic produced by the circuit. In order to do that we applied increasing vacuum suction to an experimental CPB circuit and measured the flow produced.

The aim of this study is to observe how VAVD and the size of the venous line and cannulas affect the flow in a cardiopulmonary bypass circuit.

\section{METHODS}

This is an experimental and observational study. The experimental circuit was assembled as shown in Figure 1 and it represents the normal CPB circuit routinely used during cardiac surgical procedure. The patient is mimicked by a "patient reservoir" (PR) (Midicard System, Dideco, Sorin Group, Mirandola, Italy). The venous cannula $(C)$ is positioned at the bottom of the $\mathrm{PR}$ and drained the blood into the venous reservoir (VR) positioned $50 \mathrm{~cm}$ below through a $150 \mathrm{~cm}$ long venous line (VL), mimicking the distance between the PR and the VR which is usually maintained in our Institution. The difference of height between the PR and the VR, and the length of the venous line are kept constant in all the tests. The pressure transducers were calibrated to atmosphere. Negative pressures mentioned throughout the paper are relative to atmospheric pressure.

A flow-meter (Bio-probe, transducer, Medtronic Inc, Minneapolis, MN, US) was positioned on the venous line (Figure 1). A roller pump (HLM, Cobe-Stockert, Munich, Germany) was used to pump the blood from the VR back to the PR. Wall suction was applied directly, modulated and measured into the venous reservoir (Midicard System, Dideco, Sorin Group, Mirandola, Italy) by two different systems: the first is integrated into the vacuum regulator system (Vacuum Regulator, Baxter) and the second is connected directly to the venous reservoir (Monitor Pressure Regulator, Medtronic). For this study we have measured the degree of vacuum which was applied into the venous reservoir. The circuit prime volume consisted of with group $O$ date expired re-suspended red cells and Plasmalyte 148 (Baxter, Healthcare Corp) to a hematocrit of $28 \%$ to $30 \%$ at a room temperature $\left(24 \mathrm{C}^{\circ}\right)$.

The blood re-circulated until steady state flow was reached and the flow, measured by the flowmeter, recorded. Measurements of flow were taken at the baseline (considered at siphon gravity) and subsequently, an increasing VAVD negative pressure $(-10,-20,-30,-40,-50$ and $-60 \mathrm{mmHg})$ was applied to the system and measured. Three different tests were performed changing the tubing diameter of the $V L$, which was respectively $1 / 4 ", 5 / 16 "$ and $3 / 8$ ".

Each test was repeated three times with every combination of venous cannulae and venous line tubing. We tested all the cannulae available and in use at our hospital: 1) metal angled cannulas (A)(DLP, Medtronic Inc, Minneapolis, MN, US) size 12, 14, 16, 18, 20, 24 Fr, 2) bullet-tip straight cannulas (S) (DLP, Medtronic Inc, Minneapolis, MN, US) size 12, 14, 16, 18, 20, 26 Fr. The drainage of two venous cannulae, at the same time, was also tested to mimic the bi-caval cannulation.

The mean value of the three different tests was considered in our results.

\section{RESULTS}

Three tables were generated showing the blood flow produced by each circuit according to the use of a specific cannula or a combination of cannulae and the degree of vacuum applied to the system (Table 1-3).

Resulted showed that angled cannulae drained more than the straight cannulae, increasing with increased vacuum is applied to the system. With a $1 / 4$ " venous line, a $14 \mathrm{Fr}$ straight cannula drains $30 \mathrm{ml} / \mathrm{min}$ less than a 14 French ( $\mathrm{Fr}$ ) angled one with a siphon gravity. This difference becomes $50 \mathrm{ml} / \mathrm{min}$ when vacuum -10 $\mathrm{mmHg}$ is applied to the system, 120 with $-20 \mathrm{mmHg}$ and 180 with -30 (Table 1-3).

The same single cannula (both straight (S) or angled (A)) drains more when a bigger venous line is used. As an example, with siphon gravity a $18 \mathrm{Fr}$ straight cannula drains $800 \mathrm{ml} / \mathrm{min}$ with a $1 / 4$ " venous line, 1280 with a 5/16" and 1560 with $1 / 2 "$ (Table $1-3)$.

The desired flow can be obtained by several combination of cannula size, vacuum applied to the system and size of the venous line. As an example, the flow of $1200 \mathrm{ml} / \mathrm{min}$ can be obtained with siphon gravity and a combination of angled $18 \mathrm{Fr}$ and angle 20Fr cannulae. The same flow can be achieved with a combination $16 \mathrm{Fr} \mathrm{A}-18 \mathrm{Fr} \mathrm{A}$ and $-10 \mathrm{mmHg}$ of vacuum to the system, $14 \mathrm{Fr} \mathrm{A}-14 \mathrm{Fr} \mathrm{A}$ with $-20 \mathrm{mmHg}$ or $12 \mathrm{~A}-12 \mathrm{~A}$ with $-30 \mathrm{mmHg}$ (Table 1-3).

These tables are routinely used at our Institution to choose the best venous cannula or the best combination of venous cannulae in order to achieve the desired flow, especially in cases where a minimally invasive approach has been selected. 
Vida et al. The Effect of Vacuum on Venous Drainage: an Experimental Evaluation on Pediatric Venous Cannulas and Tubing Systems

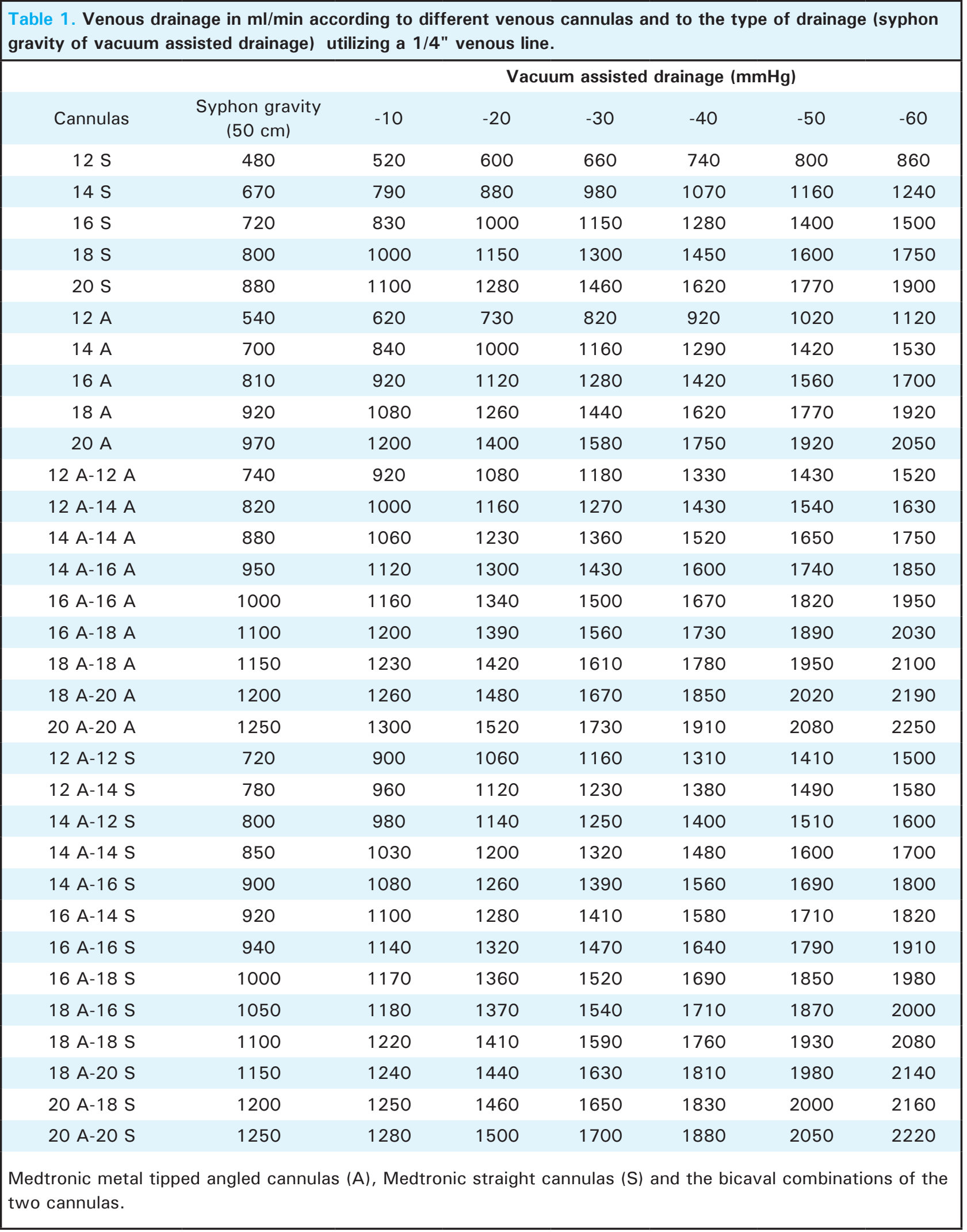


Table 2. Venous drainage in $\mathrm{ml} / \mathrm{min}$ according to different venous cannulas and to the type of drainage (syphon gravity of vacuum assisted drainage) utilizing a 5/16" venous line.

\begin{tabular}{|c|c|c|c|c|c|c|c|}
\hline \multirow[b]{2}{*}{ Cannulas } & \multirow[b]{2}{*}{$\begin{array}{c}\text { Syphon gravity } \\
(50 \mathrm{~cm})\end{array}$} & \multicolumn{6}{|c|}{ Vacuum assisted drainage $(\mathrm{mmHg})$} \\
\hline & & -10 & -20 & -30 & -40 & -50 & -60 \\
\hline $12 \mathrm{~S}$ & 620 & 800 & 880 & 950 & 1040 & 1130 & 1200 \\
\hline $14 \mathrm{~S}$ & 800 & 1140 & 1280 & 1360 & 1440 & 1500 & 1580 \\
\hline $16 \mathrm{~S}$ & 1000 & 1380 & 1560 & 1680 & 1800 & 1900 & 2020 \\
\hline $18 \mathrm{~S}$ & 1280 & 1690 & 1900 & 2050 & 2200 & 2330 & 2470 \\
\hline $20 \mathrm{~S}$ & 1570 & 2000 & 2230 & 2400 & 2580 & 2720 & 2880 \\
\hline $12 \mathrm{~A}$ & 750 & 1040 & 1210 & 1270 & 1310 & 1380 & 1460 \\
\hline $14 \mathrm{~A}$ & 980 & 1360 & 1540 & 1650 & 1740 & 1860 & 1990 \\
\hline $16 \mathrm{~A}$ & 1220 & 1640 & 1830 & 1970 & 2120 & 2270 & 2420 \\
\hline $18 \mathrm{~A}$ & 1530 & 1970 & 2180 & 2340 & 2510 & 2680 & 2850 \\
\hline $20 \mathrm{~A}$ & 1750 & 2210 & 2450 & 2640 & 2850 & 3050 & 3260 \\
\hline $12 \mathrm{~A}-12 \mathrm{~A}$ & 1400 & 1600 & 1790 & 1930 & 2060 & 2180 & 2300 \\
\hline $12 A-14 A$ & 1500 & 1900 & 2090 & 2240 & 2380 & 2520 & 2650 \\
\hline $14 \mathrm{~A}-14 \mathrm{~A}$ & 1600 & 2100 & 2290 & 2440 & 2590 & 2760 & 2900 \\
\hline $14 \mathrm{~A}-16 \mathrm{~A}$ & 1800 & 2300 & 2520 & 2700 & 2880 & 3080 & 3250 \\
\hline $16 \mathrm{~A}-16 \mathrm{~A}$ & 1900 & 2400 & 2640 & 2840 & 3040 & 3250 & 3450 \\
\hline $16 \mathrm{~A}-18 \mathrm{~A}$ & 2000 & 2550 & 2820 & 3050 & 3280 & 3530 & 3750 \\
\hline $18 \mathrm{~A}-18 \mathrm{~A}$ & 2200 & 2650 & 2910 & 3140 & 3350 & 3640 & 3850 \\
\hline $18 \mathrm{~A}-20 \mathrm{~A}$ & 2400 & 2800 & 3080 & 3330 & 3600 & 3870 & 4100 \\
\hline $20 A-20 A$ & 2600 & 3050 & 3300 & 3550 & 3800 & 4050 & 4250 \\
\hline $12 \mathrm{~A}-12 \mathrm{~S}$ & 1300 & 1500 & 1690 & 1840 & 1970 & 2090 & 2200 \\
\hline $12 \mathrm{~A}-14 \mathrm{~S}$ & 1400 & 1700 & 1900 & 2050 & 2190 & 2320 & 2450 \\
\hline $14 \mathrm{~A}-12 \mathrm{~S}$ & 1500 & 1800 & 1990 & 2140 & 2280 & 2420 & 2550 \\
\hline $14 \mathrm{~A}-14 \mathrm{~S}$ & 1600 & 2000 & 2200 & 2360 & 2510 & 2660 & 2800 \\
\hline $14 \mathrm{~A}-16 \mathrm{~S}$ & 1700 & 2200 & 2400 & 2560 & 2730 & 2900 & 3050 \\
\hline $16 \mathrm{~A}-14 \mathrm{~S}$ & 1800 & 2250 & 2460 & 2630 & 2800 & 2990 & 3150 \\
\hline $16 \mathrm{~A}-16 \mathrm{~S}$ & 1900 & 2350 & 2580 & 2770 & 2960 & 3170 & 3350 \\
\hline $16 \mathrm{~A}-18 \mathrm{~S}$ & 2000 & 2450 & 2700 & 2910 & 3120 & 3350 & 3550 \\
\hline $18 \mathrm{~A}-16 \mathrm{~S}$ & 2100 & 2500 & 2760 & 2980 & 3200 & 3440 & 3650 \\
\hline $18 \mathrm{~A}-18 \mathrm{~S}$ & 2200 & 2600 & 2860 & 3090 & 3330 & 3590 & 3800 \\
\hline $18 \mathrm{~A}-20 \mathrm{~S}$ & 2300 & 2700 & 2970 & 3210 & 3470 & 3730 & 3950 \\
\hline $20 \mathrm{~A}-18 \mathrm{~S}$ & 2400 & 2750 & 3020 & 3260 & 3520 & 3780 & 4000 \\
\hline $20 \mathrm{~A}-20 \mathrm{~S}$ & 2500 & 2900 & 3180 & 3430 & 3700 & 3970 & 4200 \\
\hline
\end{tabular}


Vida et al. The Effect of Vacuum on Venous Drainage: an Experimental Evaluation on Pediatric Venous Cannulas and Tubing Systems

\begin{tabular}{|c|c|c|c|c|c|c|c|}
\hline \multirow[b]{2}{*}{ Cannulas } & \multirow[b]{2}{*}{$\begin{array}{l}\text { Syphon gravity } \\
(50 \mathrm{~cm})\end{array}$} & \multicolumn{6}{|c|}{ Vacuum assisted drainage $(\mathrm{mmHg})$} \\
\hline & & -10 & -20 & -30 & -40 & -50 & -60 \\
\hline $16 \mathrm{~S}$ & 1200 & 1520 & 1700 & 1850 & 1950 & 2000 & 2050 \\
\hline $18 \mathrm{~S}$ & 1560 & 2080 & 2370 & 2600 & 2700 & 2800 & 2860 \\
\hline $20 \mathrm{~S}$ & 1820 & 2460 & 2800 & 3050 & 3250 & 3400 & 3500 \\
\hline $26 \mathrm{~S}$ & 2100 & 2750 & 3050 & 3300 & 3500 & 3650 & 3750 \\
\hline $16 \mathrm{~A}$ & 1400 & 1900 & 2200 & 2400 & 2500 & 2600 & 2650 \\
\hline $18 \mathrm{~A}$ & 1750 & 2400 & 2750 & 3000 & 3150 & 3300 & 3400 \\
\hline $20 \mathrm{~A}$ & 2050 & 2700 & 3050 & 3350 & 3550 & 3750 & 3900 \\
\hline $24 \mathrm{~A}$ & 2800 & 3500 & 4000 & 4450 & 4850 & 5200 & 5500 \\
\hline $16 \mathrm{~S}-16 \mathrm{~S}$ & 2200 & 2700 & 3000 & 3250 & 3500 & 3740 & 3900 \\
\hline $16 \mathrm{~S}-18 \mathrm{~S}$ & 2400 & 3000 & 3400 & 3700 & 3950 & 4200 & 4440 \\
\hline $18 \mathrm{~S}-18 \mathrm{~S}$ & 2600 & 3250 & 3700 & 4100 & 4450 & 4700 & 4920 \\
\hline $18 \mathrm{~S}-20 \mathrm{~S}$ & 2800 & 3500 & 3950 & 4370 & 4750 & 5030 & 5200 \\
\hline $20 \mathrm{~S}-20 \mathrm{~S}$ & 3000 & 3700 & 4140 & 4570 & 4930 & 5200 & 5460 \\
\hline $20 \mathrm{~S}-26 \mathrm{~S}$ & 3200 & 3850 & 4300 & 4700 & 5050 & 5400 & 5650 \\
\hline $26 \mathrm{~S}-26 \mathrm{~S}$ & 3400 & 4000 & 4460 & 4880 & 5270 & 5630 & 5900 \\
\hline $16 \mathrm{~A}-16 \mathrm{~A}$ & 2400 & 2900 & 3300 & 3580 & 3850 & 4100 & 4300 \\
\hline $16 \mathrm{~A}-18 \mathrm{~A}$ & 2600 & 3200 & 3600 & 4000 & 4300 & 4550 & 4800 \\
\hline $18 \mathrm{~A}-18 \mathrm{~A}$ & 2800 & 3450 & 3900 & 4310 & 4700 & 4980 & 5160 \\
\hline $18 \mathrm{~A}-20 \mathrm{~A}$ & 3000 & 3650 & 4100 & 4510 & 4900 & 5150 & 5380 \\
\hline $20 \mathrm{~A}-20 \mathrm{~A}$ & 3200 & 3800 & 4250 & 4650 & 5000 & 5350 & 5580 \\
\hline $20 \mathrm{~A}-24 \mathrm{~A}$ & 3500 & 4360 & 4890 & 5340 & 5750 & 6100 & 6450 \\
\hline $24 \mathrm{~A}-24 \mathrm{~A}$ & 3800 & 4660 & 5230 & 5730 & 6220 & 6640 & 7000 \\
\hline $16 \mathrm{~A}-16 \mathrm{~S}$ & 2300 & 2850 & 3220 & 3500 & 3750 & 4000 & 4160 \\
\hline $16 \mathrm{~A}-18 \mathrm{~S}$ & 2500 & 3100 & 3500 & 3850 & 4120 & 4350 & 4550 \\
\hline $18 \mathrm{~A}-16 \mathrm{~S}$ & 2600 & 3150 & 3550 & 3900 & 4200 & 4450 & 4690 \\
\hline $18 \mathrm{~A}-18 \mathrm{~S}$ & 2700 & 3350 & 3800 & 4200 & 4550 & 4800 & 5030 \\
\hline $18 \mathrm{~A}-20 \mathrm{~S}$ & 2800 & 3550 & 4000 & 4420 & 4800 & 5070 & 5270 \\
\hline $20 \mathrm{~A}-18 \mathrm{~S}$ & 3000 & 3600 & 4050 & 4470 & 4850 & 5130 & 5320 \\
\hline $20 \mathrm{~A}-20 \mathrm{~S}$ & 3100 & 3750 & 4190 & 4600 & 4950 & 5240 & 5500 \\
\hline $24 \mathrm{~A}-18 \mathrm{~S}$ & 3300 & 4100 & 4570 & 5000 & 5390 & 5750 & 6050 \\
\hline $24 \mathrm{~A}-20 \mathrm{~S}$ & 3400 & 4200 & 4680 & 5110 & 5520 & 5880 & 6200 \\
\hline $24 \mathrm{~A}-26 \mathrm{~S}$ & 3700 & 4250 & 4780 & 5230 & 5650 & 6000 & 6350 \\
\hline
\end{tabular}




\section{DISCUSSION}

Vacuum-assisted venous drainage is a widely used technique that cardiac surgeons and the perfusion team components use to reduce haemodilution ${ }^{2-5,10}$ and to reduce the size of the cannulae during minimally invasive cardiac surgery (MICS). ${ }^{5-7}$ Such assisted venous drainage allows to decrease the declivity of the reservoir, and thus, to significantly decrease the length of the venous, arterial and suction lines. The result is a shorter and smaller tubing system with a reduced priming volume. ${ }^{3}$ Furthermore, VAVD has proven to increase the venous return through cannulae that demonstrate limited flow capacity under siphon drainage conditions. ${ }^{11}$

During MICS, surgeons perform surgical procedures through small incisions. To allow this approach, VAVD has become increasingly important in order to reduce the caliber of the venous cannulae while maintaining an adequate blood flow. ${ }^{6-8,12}$

Although the use of VAVD during MICS is used all over the world by adult and pediatric cardiac surgeons, its use is not uniform and varies according to the surgeon's or Institution experience.

Several reports in literature focused on studying the effect of the different negative pressures, applied to the system, on the flow produced by a CPB circuit. ${ }^{11-16}$ Kurusz and coworkers ${ }^{22}$ tested different femoral cannulae and assessed how their position (in inferior vena cava rather than in the right atrium) and the increasing negative pressure applied to the system affects the venous drainage flow. They concluded that the position of the cannula, rather than the design has effects on flow, that every cannula is capable of achieving higher flow when negative pressure is applied. ${ }^{11-16}$ The pressure inside the reservoir is lower than the pressure at the tip of the venous cannula, in fact it is a combination of both siphon gravity and the applied vacuum pressure, thus increasing the drainage capabilities of each cannula.

We tested how the CPB flow changes when different negative pressures are applied to the system and different $\mathrm{VL}$ sizes. We produced three tables, one for each diameter of venous tubing, showing the maximum flow achieved with every venous cannula or combinations of cannulae at different negative pressures. In MICS, the use of small cannulae can drastically improve the approach to intra-thoracic structures. Our study shows that the same flow can be reached despite using cannulae (in some occasions even two sizes smaller) by adapting the amount of negative pressure applied to the venous system. ${ }^{6-8}$ The angled cannulae have proven to drain more than a straight tip cannula of the same size. This allows both the surgeon and the perfusion team component to choose the right combination of cannula to achieve a desirable CPBP flow.

These tables are routinely used at the University of Padua in the Pediatric Cardiac Surgery Program to choose the best combination of venous cannulae and negative pressure according to the size of the surgical access and the size of the vena cavae, in order to achieve the desired theoretical flow. As an example, during MICS, with the aid of a maximum of $50 \mathrm{mmHg}$ of vacuum, obtained either by a wall vacuum system or a centrifugal pump were are usually able to minimize the size of tubing and venous cannulas, which were usually 1-2 under the estimated size for patient's BSA).

We acknowledge this study presents some limitations. This is an experimental in-vitro study whose results may significantly differ from an in-vivo one. In fact, the maximum flow reported has been achieved in a "perfect position scenario", which might be due to the fact the cannulae have been positioned at the bottom of the patient-reservoir excluding any chattering or collapsing effect which is present in-vivo.

Another limitation we identified is that only cannulae available in our Institution (because routinely used in-vivo) were tested. We understand that different cannulae with different drainage capability could produce different flows when used in the same setting.

In conclusion, the vacuum assisted venous drainage allows the use smaller cannulae maintaining a good venous return, which proves very useful during minimally invasive approaches. The present study should be considered as a preliminary attempt to create a scientific-based starting point for a uniform the use of VAVD. 


\section{REFERENCES}

1. Munster K, Andersen U, Mikkelsen J, Pettersson G. Vacuum-assisted venous drainage (VAVD). Perfusion 1999;14:419-23.

2. Taketani S, Sawa Y, Masai T, et al. A novel technique for cardiopulmonary bypass using vacuum system for venous drainage with pressure relief valve: an experimental study. Artif Organs 1998;22:337-341

3. Durandy Y. Perfusionist strategies for blood conservation in pediatric cardiac surgery World J Cardiol 2012;26;2(2):27-33

4. Sistino JJ, Michler RE, Mongero LB. Laboratory evaluation of a low prime closed-circuit cardiopulmonary bypass system. J Extra-Corpor Technol 1993;24:116-19.

5. Bevilacqua S, Matteucci S, Ferrarini M, et al. Biochemical evaluation of vacuum-assisted venous drainage: a randomized, prospective study. Perfusion 2002;17(1):57-61.

6. Vida VL, Padalino MA, Motta R, Stellin G. Minimally invasive surgical options in pediatric heart surgery. Expert Rev Cardiovasc Ther 2011;9(6):763-9.

7. Vida VL, Padalino MA, Bhattarai A, Stellin G. Right posterior-lateral mini-thoracotomy access for treating congenital heart disease. Ann Thorac Surg 2011;92(6):2278-80.

8. Vida VL, Padalino MA, Boccuzzo G, at al. Minimally invasive surgery for congenital heart disease: a gender differentiated approach. J Thorac Cardiovasc Surg $2009 ; 138(4): 933-6$.

9. Nakanishi K, Shichijo T, Shinkawa Y, et al. Usefulness of vacuum-assisted cardiopulmonary bypass circuit for pediatric open-heart surgery in reducing homologous blood transfusion. Eur J Cardiothorac Surg 2001;20:233-238
10. Gregoretti S. Suction-induced hemolysis at various vacuum pressures: implications for intraoperative blood salvage. Transfusion 1996;36:57-60.

11. Fiorucci A, Gerometta PS, DeVecchi M, Guzman C, Costantino ML, Arena V. In vitro assessment of the vacuum-assisted venous drainage (VAVD) system: risks and benefits. Perfusion 2004;19(2):113-7.

12. Shin $H$, Yozu R, Maehara $T$, et al.Vacuum assisted cardiopulmonary bypass in minimally invasive cardiac surgery: its feasibility and effects on haemolysis. Artif Organs 2000;24:450-53.

13. Lau CL, Posther KE, Stephenson GR, et al. Mini-circuit cardiopulmonary bypass with vacuum assisted venous drainage. Feasibility of an asanguineous prime in the neonate. Perfusion 1999;14:389-96.

14. Kiyama H, Imazeki T, Katayama $\mathrm{Y}$, Murai N, Mukouyama $M$, Yamauti N. Vacuum-assisted venous drainage in single-access minimally invasive cardiac surgery. J Artif Organs $2006 ; 6(1): 20-4$.

15. Colangelo N, Torracca L, Lapenna E, Moriggia S, Crescenzi G, Alfieri O. Vacuum-assisted venous drainage in extrathoracic cardiopulmonary bypass management during minimally invasive cardiac surgery. Perfusion $2006 ; 21(6): 361-5.9$

16. Kurusz M, Deyo DJ, Sholar AD, Tao W, Zwischenberger JB. Laboratory testing of femoral venous cannulae: effect of size, position and negative pressure on flow. Perfusion $1999 ; 14: 379-387$. 